\title{
NANO VITROCERÂMICA DE ESCÓRIA DE ACIARIA
}

\section{Eduardo Bellini Ferreira* e Edgar Dutra Zanotto}

Departamento de Engenharia de Materiais, Universidade Federal de São Carlos, Via Washington Luis, km 235, 13565-905 São Carlos - SP

Luis Augusto Marconi Scudeller

Centro de Pesquisa e Desenvolvimento, USIMINAS, BR 381, km 210, 35160-900 Ipatinga - MG

Recebido em 18/6/01; aceito em 14/11/01

\begin{abstract}
GLASS-CERAMIC FROM STEELMAKING SLAG. The manufacture of glass-ceramics is an alternative route for the commercial use of metallurgical slags. Such types of glass-ceramics may find commercial applications owing to their low cost, good mechanical properties and superior visual aspect. Besides, due to the elimination of that industrial residue from the environment and also due to the possibility of replacement of natural stones such as marbles and granites, the use of slags is an activity with strong ecological appeal. While the use of blast-furnace slags for the production of glass-ceramics is well known, the utilization of steel making slags constitutes a challenge, because these materials possess low concentration of $\mathrm{SiO}_{2}$. In this work a novel composition for producing glasses and glass-ceramics from a steelmaking slag is presented. The crystal nucleation kinetics, the characterization of the resulting microstructures for two different thermal treatments and mechanical properties of the glass-ceramics are discussed. A glass-ceramic having a marble aspect, fine volumetric crystallization, high degree of crystallization and improved mechanical strength was obtained.
\end{abstract}

Keywords: steelmaking slag; glass; glass-ceramic.

\section{INTRODUÇÃO}

Encontrar aplicações para rejeitos industriais ao invés de descartálos vem ganhando importância no atual modelo de gerenciamento ecológico das empresas. As companhias siderúrgicas, em especial, enfrentam dificuldades para manejar a grande quantidade de resíduos, de diferentes composições, gerada pelo processo de fabricação de aço. $\mathrm{O}$ descarte desses resíduos acarreta enorme gasto energético para o transporte do material e o controle de áreas adequadas para depósito, além de sofrer crescente pressão social para sua diminuição e, futuramente, total eliminação do processo.

Vitrocerâmicas são materiais policristalinos produzidos a partir da cristalização controlada de artigos de vidro. O controle da microestrutura, característico desse processo, é uma poderosa ferramenta de engenharia de materiais, que permite a obtenção de produtos com excelentes propriedades. Além disso, os vidros suportam grandes quantidades de elementos diferentes em solução, sendo, portanto, ideais para assimilar escórias complexas em suas composições. Os materiais assim produzidos podem, em princípio, ter propriedades mecânicas e aspecto visual atraentes e ser utilizados como revestimento na construção civil e em aplicações industriais.

Além da escória de alto forno, outro rejeito que provém do processo siderúrgico em grande quantidade é a escória gerada no refino do aço, em conversor LD, denominada escória de aciaria. Em uma planta siderúrgica do porte da Usiminas, aproximadamente $25.000 \mathrm{t} /$ mês dessa escória são geradas, mas ainda não existe um processo para a sua reutilização como matéria-prima. O uso de escória de alto forno para a fabricação de vitrocerâmicas é bem conhecido ${ }^{1-3}$, mas a utilização de escória de aciaria para o mesmo fim ainda constitui-se em um desafio. A escória de aciaria possui baixa concentração de $\mathrm{SiO}_{2}$ e composição química variável, o que limita o seu uso. A Tabe-

\footnotetext{
*e-mail: pebf@iris.ufscar.br
}

la 1 apresenta as composições de uma escória de alto forno típica e da escória de aciaria utilizada nesse trabalho, produzidas na Usiminas, para comparação.

Tabela 1. Composições de escórias (\% em peso)

\begin{tabular}{ccccc}
\hline Componente & $\begin{array}{c}\text { Escória de } \\
\text { alto forno }\end{array}$ & $\begin{array}{c}\text { Escória de } \\
\text { aciaria }\end{array}$ & Kislitsyn $^{4}$ & Rabinovich $^{5}$ \\
\hline $\mathrm{SiO}_{2}$ & 33,3 & 10,3 & 31,9 & 15,8 \\
$\mathrm{Al}_{2} \mathrm{O}_{3}$ & 12,7 & 3,9 & 3,9 & 5,2 \\
$\mathrm{Fe}_{2} \mathrm{O}_{3}$ & 0,4 & 11,2 & - & 28,5 \\
$\mathrm{FeO}$ & - & 15,8 & 10,8 & - \\
$\mathrm{CaO}$ & 44,8 & 38,7 & 27,9 & 35,9 \\
$\mathrm{MgO}$ & 6,3 & 8,2 & 17,1 & 6,4 \\
$\mathrm{MnO}$ & 0,4 & 5,4 & 7,7 & - \\
$\mathrm{MnO}$ & - & - & - & 6,2 \\
$\mathrm{TiO}_{2}$ & - & 1,0 & 0,3 & 0,9 \\
$\mathrm{Na}_{2} \mathrm{O}$ & - & - & 0,3 & 0,5 \\
$\mathrm{~K}_{2} \mathrm{O}$ & - & - & 0,1 & - \\
$\mathrm{Cr}_{2} \mathrm{O}_{3}$ & - & - & 2,0 & - \\
$\mathrm{P}_{2} \mathrm{O}_{5}$ & - & 1,7 & - & - \\
$\mathrm{SO}_{3}$ & - & - & - & 0,4 \\
$\mathrm{~S}^{2-}$ & - & 0,2 & 0,2 & - \\
\hline
\end{tabular}

No início dos anos 80, Kislitsyn et al. ${ }^{4}$ obtiveram uma vitrocerâmica a partir da escória produzida em um forno tipo Siemens-Martin, que também contém uma alta concentração de ferro, como a escória de aciaria, mas possui concentração de $\mathrm{SiO}_{2}$ significativamente maior (ver Tabela 1). As propriedades físicas do material produzido foram comparáveis às de vitrocerâmicas de escória de alto-forno comerciais, existentes na época. Entretanto, esse tipo de forno atualmente está em desuso nas usinas siderúrgicas. 
Rabinovich ${ }^{5}$ também produziu vitrocerâmicas de escória de aciaria, embora não se conheçam produtos comerciais derivados de seu trabalho. A composição da escória por ele utilizada pode ser vista na Tabela 1. Segundo esse autor ${ }^{5}$, vitrocerâmicas contendo até $29 \%$ em peso de $\mathrm{Fe}_{2} \mathrm{O}_{3}$ foram desenvolvidas. Uma das composições de vidro por ele projetada continha FeS como agente nucleante e, aparentemente, o óxido de manganês também atuou como catalisador da cristalização. Os vidros projetados foram fundidos entre $1550 \mathrm{e}$ $1580{ }^{\circ} \mathrm{C}$, e vertidos em um molde de metal, formando placas de $15 \mathrm{x}$ $15 \times 0,7 \mathrm{~cm}^{3}$, que foram recozidas em um forno previamente aquecido a $500-550{ }^{\circ} \mathrm{C}$, imediatamente depois da conformação. Essas placas foram cristalizadas pelo aquecimento lento até $1100{ }^{\circ} \mathrm{C}$ e um patamar de $1 \mathrm{~h}$ nessa temperatura.

Assim, o Laboratório de Materiais Vítreos (LaMaV) da Universidade Federal de São Carlos (UFSCar) e a Usiminas associaram-se em um projeto conjunto de desenvolvimento de vidros e, posteriormente, de vitrocerâmicas, que contenham a escória de aciaria como matéria-prima principal.

Para a otimização dos tratamentos térmicos de cristalização e a transformação do vidro em vitrocerâmica, é necessário conhecer sua cinética de cristalização, dada pelas taxas de nucleação e crescimento de cristais em função da temperatura. Entretanto, devido ao complexo comportamento de cristalização dos vidros de escória, não é prático utilizar o método tradicional de medida direta, por microscopia, do número e dimensões dos cristais em amostras submetidas a diferentes tratamentos térmicos. Utilizamos então um método indireto para a determinação da curva de nucleação em função da temperatura, com o auxílio de Calorimetria Exploratória Diferencial, ou DSC. Esse método consiste em medir a temperatura do pico de cristalização obtida das curvas de DSC de amostras tratadas previamente, em várias temperaturas, durante um tempo fixo, na faixa de nucleação do material (normalmente, ao redor de $\mathrm{T}_{\mathrm{g}}$ - a temperatura de transição do vidro).

Vários autores ${ }^{6-11}$ estudaram a possibilidade de se obter informações sobre a cinética de nucleação de vidros utilizando análises térmicas (Análise Térmica Diferencial ou ATD e DSC) ao invés de medidas diretas do número de núcleos resultante de tratamentos térmicos prévios das amostras. Especificamente, Ray e Day ${ }^{11}$ mostraram que os pontos em um gráfico do inverso da temperatura do pico de cristalização das curvas de ATD, $\mathrm{T}_{\mathrm{c}}^{-1}$, em função da temperatura, $\mathrm{T}_{\mathrm{n}}$, de tratamentos térmicos prévios na faixa de nucleação, ajustam-se qualitativamente bem à curva de nucleação do vidro $\mathrm{Na}_{2} \mathrm{O} .2 \mathrm{CaO} .3 \mathrm{SiO}_{2}$, o que não acontece quando se utiliza a intensidade do pico, $\delta \mathrm{T}_{\mathrm{c}}$, para o mesmo fim, nesse sistema. Isso acontece, pois o desvio da temperatura do pico de cristalização, causado pelo tratamento na faixa de nucleação, em relação à temperatura do pico de amostras sem tratamento, é proporcional ao número de núcleos formados durante esse tratamento, enquanto que o desvio na intensidade dos picos sofre a influência da sobreposição do crescimento dos cristais, não produzindo o mesmo resultado. Quanto mais núcleos estiverem presentes durante a etapa de crescimento de cristais, maior será o desvio do pico de cristalização na curva DSC em direção a temperaturas mais baixas. Portanto, do gráfi-

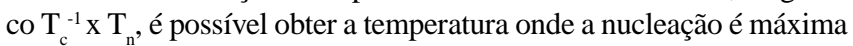
e, também, a faixa de temperatura onde ela ocorre.

Com o auxílio dos resultados obtidos por DSC neste trabalho, vários tratamentos térmicos foram planejados, resultando em amostras finamente cristalizadas, as quais tiveram suas propriedades mecânicas avaliadas em ensaios de flexão a três pontos e comparadas com amostras do material vítreo.

\section{PARTE EXPERIMENTAL}

O desenvolvimento de uma vitrocerâmica inicia-se pela obten- ção do vidro do qual ela se originará por cristalização. Para isso, adicionou-se areia à escória de aciaria, para aumentar a concentração de $\mathrm{SiO}_{2}$ na mistura e facilitar a vitrificação, e $\mathrm{Na}_{2} \mathrm{CO}_{3}$, como fundente. Várias composições foram preparadas, variando-se a proporção de escória, areia e carbonato de sódio nas misturas.

As fusões foram realizadas em temperaturas que variaram de $1200{ }^{\circ} \mathrm{C}$ a $1450{ }^{\circ} \mathrm{C}$, em fornos de laboratório com carregamento pela base, em cadinhos de $\mathrm{ZAS}\left(\mathrm{ZrO}_{2}-\mathrm{Al}_{2} \mathrm{O}_{3}-\mathrm{SiO}_{2}\right)$ confeccionados no próprio LaMaV.

Uma dessas composições, contendo nominalmente $60 \% \mathrm{em}$ peso de escória de aciaria, $35 \%$ de areia e $5 \%$ de $\mathrm{Na}_{2} \mathrm{O}$ (após a fusão), resultou em um vidro com bom comportamento de fusão e conformação de amostras (ou seja, não devitrificou facilmente e apresentou razoável homogeneidade), além de apresentar cristalização no volume. Placas de aproximadamente $5 \times 5 \times 1 \mathrm{~cm}^{3}$ foram confeccionadas. Este vidro foi então escolhido para estudos mais detalhados.

Os tratamentos térmicos para nucleação e as análises de DSC para a determinação das temperaturas características e da curva de nucleação do material foram realizados em um DSC 404, Netzsch, em amostras de aproximadamente $30 \mathrm{mg}$, pulverizadas entre malhas \#50 (300 $\mu \mathrm{m})$ e \#80 (175 $\mu \mathrm{m})$, e com velocidade de aquecimento de $20^{\circ} \mathrm{C} / \mathrm{min}$. Os tratamentos isotérmicos para nucleação foram realizados no próprio equipamento de análise térmica, durante um período fixo de $3 \mathrm{~h}$, e com velocidade de aquecimento também de $20^{\circ} \mathrm{C} /$ min, antes e depois do patamar de temperatura.

Tratamentos térmicos de cristalização em amostras para flexão foram realizados no intervalo de temperaturas de 610 a $750{ }^{\circ} \mathrm{C}$, em um forno tubular, com patamar de temperatura constante na sua região central, de comprimento suficiente para conter todas as amostras na mesma temperatura, com precisão de $\pm 2{ }^{\circ} \mathrm{C}$.

Após os tratamentos, os corpos de prova, com dimensões próximas a $3 \times 3 \times 30 \mathrm{~mm}^{3}$, foram desbastados em SiC 500 (na forma de pó), em todas as faces longas, e tiveram os cantos que seriam submetidos a tensões de tração (no ensaio de flexão) desbastados com lixa \#600, para normalização dos defeitos nas arestas, garantindo assim a mesma condição inicial em todas as amostras.

Ensaios mecânicos de flexão a três pontos foram realizados segundo a norma ASTM F417-78 (reaprovada em 1991), em uma máquina de ensaios Instron $5500 \mathrm{R}$, com velocidade de $0,5 \mathrm{~mm} / \mathrm{min}$.

As análises de microestruturas foram realizadas em um microscópio eletrônico de varredura (MEV) Zeiss DSM 940A e em um Leica/Cambridge Stereoscan 440. As análises de difração de raios X foram realizadas em um difratômetro Siemens D5000, em amostras finamente pulverizadas.

\section{RESULTADOS E DISCUSSÃO}

A Figura 1 mostra a curva DSC típica de um pedaço monolítico de vidro de escória de aproximadamente $40 \mathrm{mg}$. Um pico exotérmico de cristalização estreito e intenso, gerado por amostra monolítica, é um forte indício de cristalização no volume. Esse parece ser o caso do primeiro pico exotérmico da Figura 1, o que é de bastante interesse quando se procura obter vitrocerâmicas cristalizadas internamente. A micrografia da Figura 2 mostra a ocorrência de fina cristalização no volume do vidro, após tratamento térmico, com cristais aproximadamente esféricos e com diâmetros de aproximadamente 150 $\mathrm{nm}$. Análises por difração de raios X indicaram a presença de augita modificada como a principal fase cristalina formada. Alternativamente, pode-se supor que duas ou mais soluções sólidas de piroxênios, com composição próxima à da augita, com pequenas diferenças de estrutura e composição química, estejam presentes simultaneamente. O segundo pico exotérmico, localizado a $897^{\circ} \mathrm{C}$ na curva DSC, 
corresponde à cristalização de wollastonita como uma segunda fase minoritária, também detectada por difração de raios X.

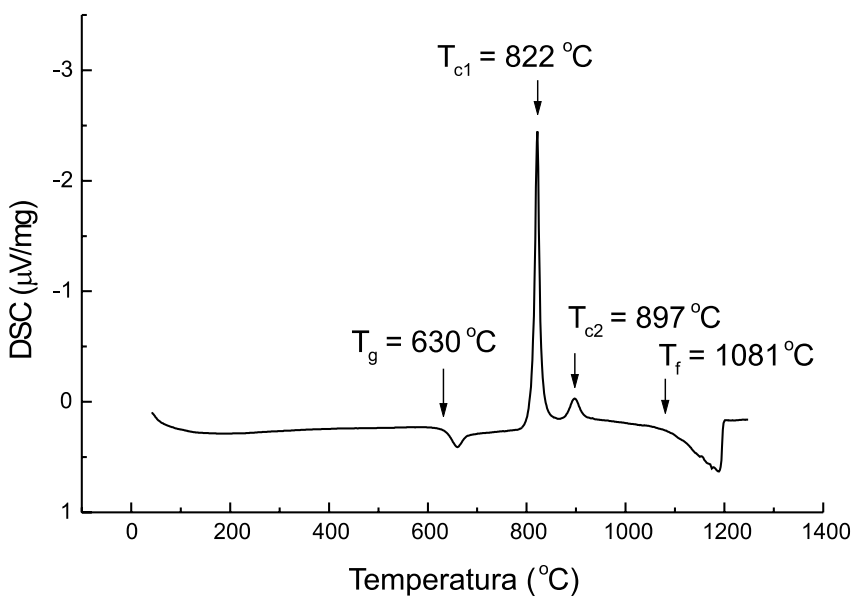

Figura 1. Curva de DSC de pedaço monolítico do vidro de escória; $20^{\circ} \mathrm{C} /$ $\min$

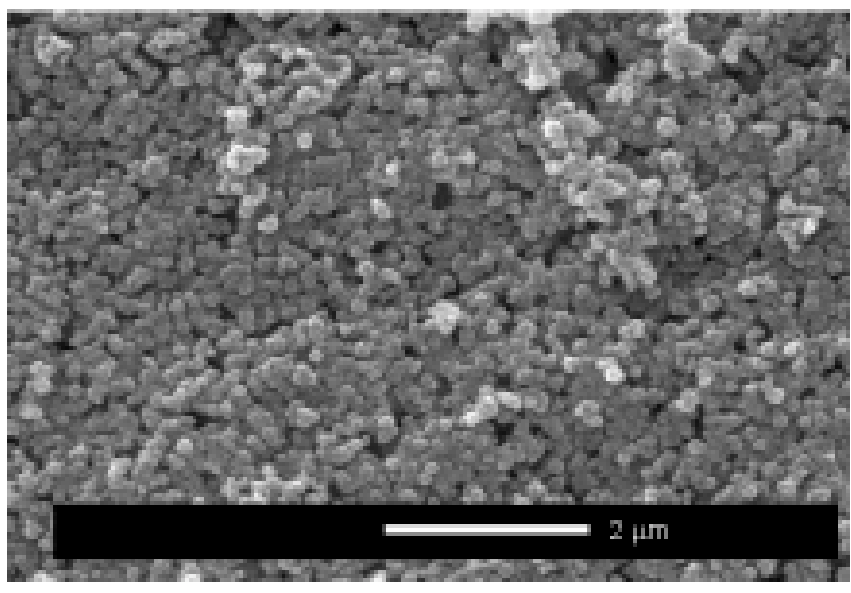

Figura 2. Micrografia do volume de uma amostra de vidro de escória tratado a $691{ }^{\circ} \mathrm{C}$ por $3 \mathrm{he} 750^{\circ} \mathrm{C}$ por $2 \mathrm{~h} . \mathrm{MEV}$ da superfície de fratura atacada em solução aquosa $0,2 \%$ vol. $\mathrm{HCl}$ e $0,8 \% \mathrm{vol}$. $\mathrm{HF}$, por $10 \mathrm{~s}$

Os cristais bastante finos encontrados no vidro de escória (devido à alta taxa de nucleação) e a heterogeneidade na distribuição dos mesmos, que decorre da dificuldade de homogeneizar o fundido, dificultaram o uso de microscopia ótica para a determinação da cinética de cristalização e impediram a obtenção de resultados reprodutíveis com o MEV. Portanto, para otimizar os tratamentos térmicos de cristalização, utilizou-se análises de DSC para a determinação qualitativa da curva de nucleação em função da temperatura.

A Figura 3 mostra o conjunto de curvas de DSC das amostras submetidas a tratamentos térmicos de nucleação, comparadas com a curva de uma amostra sem tratamento.

A Figura 4 mostra valores de $\mathrm{T}_{c}^{-1}$ em função de $\mathrm{T}_{\mathrm{n}}$ para o vidro. A visualização da faixa de nucleação, situada entre 600 e $660{ }^{\circ} \mathrm{C}$, é evidente. A figura mostra que a curva de nucleação atinge um regime aproximadamente constante após $660^{\circ} \mathrm{C}$. Esse comportamento resulta da saturação de sítios, que pode ocorrer durante a rampa de aquecimento, antes de atingir o patamar de temperatura constante no DSC e é, possivelmente, devido à nucleação heterogênea. O comportamento de cristalização de diversos vidros de escória de aciaria foi analisado por Ferreira et al. ${ }^{12}$. Esses autores observaram uma forte influência da atmosfera oxidante durante as fusões e tratamentos

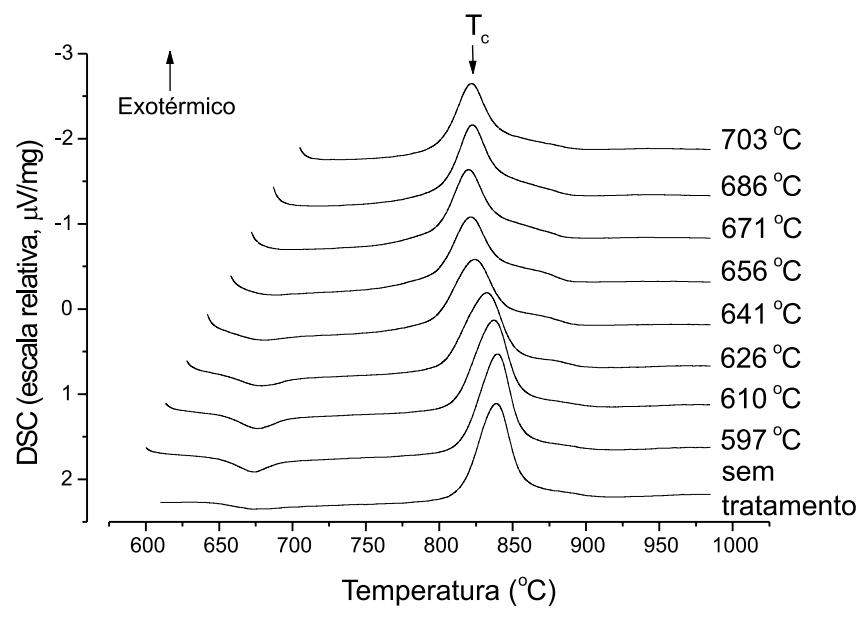

Figura 3. Curvas de DSC de amostras tratadas termicamente a diferentes temperaturas, $T_{n}$, comparadas com uma amostra sem tratamento, mostrando o deslocamento do primeiro pico de cristalização devido à nucleação promovida pelo tratamento

térmicos, devido à alta concentração de ferro nesses vidros. A razão $\mathrm{Fe}^{2+} / \mathrm{Fe}^{3+}$ é determinante da intensidade de nucleação. A nucleação de cristais de augita é provavelmente induzida pela precipitação espontânea de um espinélio, tal como a magnetita ou fase semelhante. A oxidação de $\mathrm{Fe}^{2+}$ a $\mathrm{Fe}^{3+}$ e a precipitação de espinélio podem ocorrer simultaneamente no intervalo de nucleação mostrado pela Figura 4, mas a análise desses efeitos será realizada em trabalho futuro.

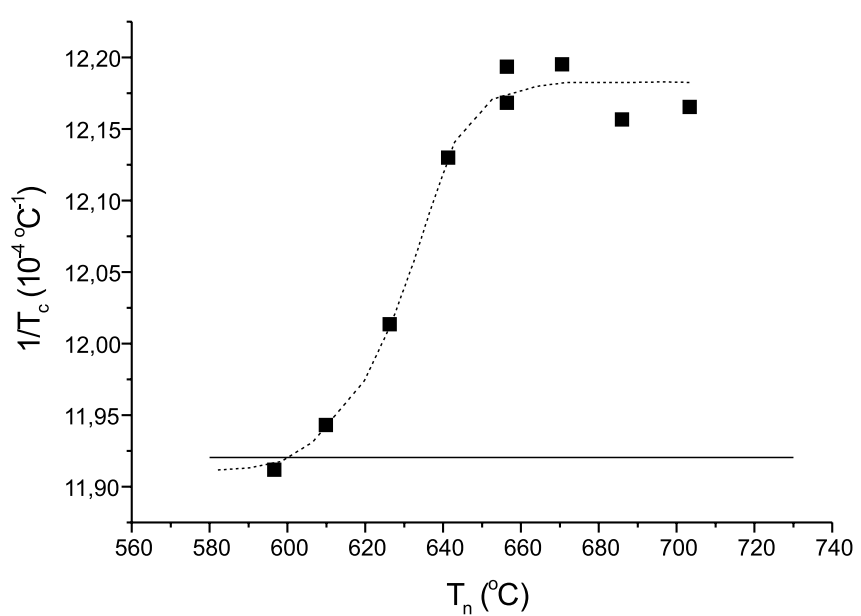

Figura 4. Gráfico do inverso da temperatura de cristalização (1/T), obtida por DSC, em função da temperatura de tratamento térmico prévio $\left(T_{n}\right)$. Legenda: (-) dados DSC, (---) apenas para guiar os olhos; (-) patamar de $1 / T_{c}$ para a amostra sem tratamento

Após a determinação da curva de nucleação, foi possível projetar tratamentos térmicos visando a maximização da cristalização. Amostras do vidro de escória foram, então, submetidas a diferentes tratamentos térmicos para comparação.

Os tratamentos térmicos foram realizados em duas etapas: entre 610 e $720^{\circ} \mathrm{C}$, por $3 \mathrm{~h}$, para nucleação, e entre 745 e $750{ }^{\circ} \mathrm{C}$, por $1 \mathrm{~h}$, para crescimento dos cristais. A temperatura de nucleação foi escolhida de acordo com a Figura 4, referente ao intervalo de temperaturas onde a nucleação parecia ser mais atuante. A temperatura de crescimento de cristais foi determinada por tentativa e erro, com base na curva de DSC da Figura 1, correspondendo a uma temperatura inter- 
mediária entre $\mathrm{T}_{\mathrm{g}} \mathrm{e} \mathrm{T}_{\mathrm{cl}}$. As amostras tratadas foram então preparadas para testes de flexão e para análise microestrutural.

Pode-se observar na Figura 5 a média da resistência mecânica à flexão a três pontos para amostras cristalizadas, comparadas com amostras vítreas (sem tratamento), para as quais a temperatura de nucleação foi considerada como sendo de $25^{\circ} \mathrm{C}$, apenas para permitir a visualização no gráfico e comparação (atentar para o fato de que essas amostras não foram submetidas a crescimento em $750{ }^{\circ} \mathrm{C}$ por $1 \mathrm{~h}$, como é o caso das amostras cristalizadas).

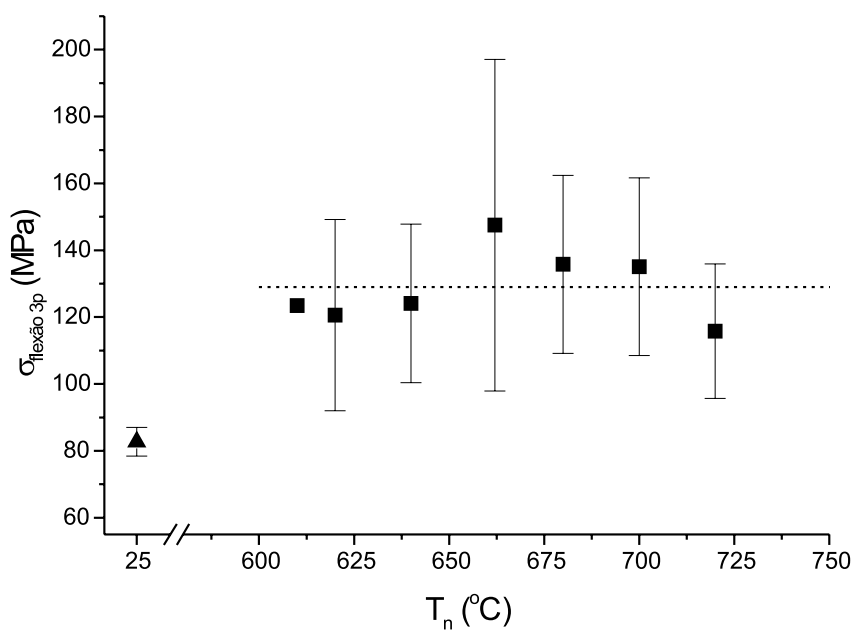

Figura 5. Resistência à flexão a três pontos de amostras cristalizadas (nucleadas por $3 \mathrm{~h} \mathrm{em} T_{n}$ mais $1 \mathrm{~h} \mathrm{em} 745-750^{\circ} \mathrm{C}$ ), comparadas com amostras vítreas $\left(T_{n}=25^{\circ} \mathrm{C}\right.$, para visualização no gráfico). Legenda: $(\mathbf{\Delta})$ vidro; $(\mathbf{\square})$ vitrocerâmicas; (---) média vitro-cerâmicas

É claramente observado na Figura 5 que a cristalização produz um aumento de aproximadamente $50 \%$ na resistência à flexão média do material (de $83 \pm 4 \mathrm{MPa}$ para $128 \pm 9 \mathrm{MPa}$ ). Esse é um resultado bastante significante e sugere a possibilidade de se utilizar escórias de aciaria como matéria-prima para produzir vitrocerâmicas com bom desempenho mecânico. No entanto, o grande espalhamento dos dados (típico de $\sigma_{\mathrm{f}}$ ) não permitiu observar correlação entre a resistência mecânica das amostras cristalizadas e a temperatura de nucleação.

A Figura 6 a mostra uma micrografia onde uma amostra tratada em $630-635^{\circ} \mathrm{C}$ por $3 \mathrm{~h}$ e a $745-750{ }^{\circ} \mathrm{C}$ por $1 \mathrm{~h}$ aparece substancialmente cristalizada. Isso demonstra que o tratamento realizado foi efetivo no sentido de promover um alto grau de cristalização volumétrica. No entanto, observa-se porosidade, que pode advir de degaseificação durante a cristalização.

A Figura $6 \mathrm{~b}$ mostra a microestrutura de uma vitrocerâmica obtida após tratamento em $730-735^{\circ} \mathrm{C}$ por $3 \mathrm{~h}$ e $745-750{ }^{\circ} \mathrm{C}$ por $1 \mathrm{~h} . \mathrm{O}$ material também foi efetivamente cristalizado com esse tratamento mas, a despeito da diferença entre as temperaturas utilizadas, apresentou tamanhos de cristais similares aos da Figura 6a. Isso confirma, de certa maneira, os resultados obtidos de resistência mecânica, que indicaram que os diferentes tratamentos térmicos nesse intervalo não produzem diferenças sensíveis nas microestruturas das amostras. Observam-se, no entanto, diferenças na porosidade resultante dos dois tratamentos, que mesmo assim não causaram diferenças significativas na resistência mecânica.

Também foram realizados ensaios de flexão a 3 pontos em amostras com tratamentos de 1 a $3 \mathrm{~h}$ entre 660 e $700{ }^{\circ} \mathrm{C}$, sem tratamento posterior em $750{ }^{\circ} \mathrm{C}$. Pode-se observar que a média das resistências mecânicas dessas amostras permaneceu no nível da resistência mecânica do material vítreo, sem tratamento. Além disso, amostras sub-
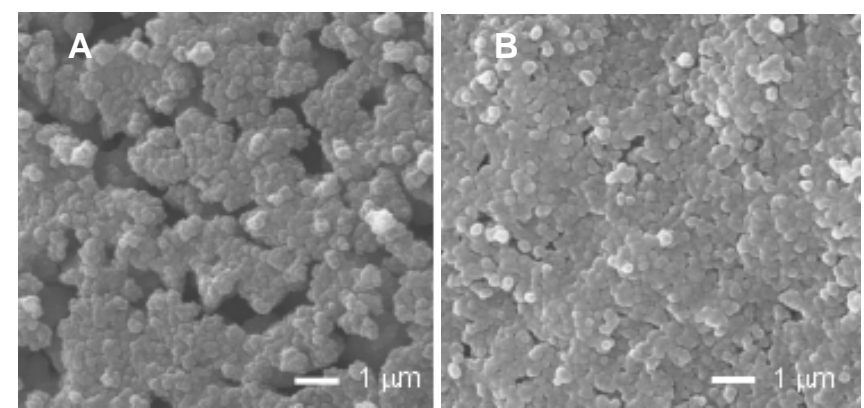

Figura 6. Microestruturas de amostras de vitrocerâmicas de escória, nucleadas em a) $630-635^{\circ} \mathrm{C} / 3 \mathrm{~h}$ e b) $730-735^{\circ} \mathrm{C} / 3 \mathrm{~h}$, e tratadas em $745-750^{\circ} \mathrm{C} / 1 \mathrm{~h}$ para crescimento dos cristais. $M E V$ das superficies de fratura atacadas em solução aquosa 0,2\% vol. HCl e 0,8\% vol. HF, por a) $20 \mathrm{~s}$ e b) $15 \mathrm{~s}$

metidas a um tratamento térmico em $750{ }^{\circ} \mathrm{C}$ por $4 \mathrm{~h}$, sem tratamento prévio de nucleação, atingiram valores de resistência mecânica tão altos quanto aqueles das amostras que tinham recebido tratamento de nucleação. Assim, parece que a resistência mecânica das vitrocerâmicas de escória é muito mais dependente da segunda etapa do tratamento, em temperatura mais alta, que causa a efetiva cristalização do material, não sendo importante o patamar na faixa de 610$720{ }^{\circ} \mathrm{C}$. Isso ocorre porque, provavelmente, a nucleação se dá de forma bastante rápida, ou o crescimento se dá a partir de núcleos pré-existentes, de forma que mesmo durante a etapa de aquecimento consegue-se a saturação do número de núcleos, a partir dos quais os cristais irão posteriormente se desenvolver. Os detalhes do que pode estar acontecendo, na realidade, ainda permanecem como alvo de estudos mais aprofundados em nossos laboratórios, que devem produzir explicações mais definitivas.

Considerando que os vidros possuem tenacidade à fratura, $\mathrm{K}_{\mathrm{IC}}$, tipicamente entre 0,7 e 0,9 MPa.m ${ }^{1 / 2}$, o tamanho da falha superficial, c, responsável pela fratura pode ser estimada pela Equação (1), utilizando-se a resistência mecânica média obtida experimentalmente, $\bar{\sigma}=83 \pm 4 \mathrm{MPa}$.

$\mathrm{c} \approx \frac{1}{\pi}\left(\frac{\mathrm{K}_{\mathrm{IC}}}{1,12 \bar{\sigma}}\right)^{2}$

Os tamanhos de defeitos assim calculados encontram-se entre 16 e $33 \mu \mathrm{m}$, o que está de acordo com o máximo diâmetro de partícula, de $35 \mu \mathrm{m}$, do SiC 500, que foi utilizado para desbastar a superfície das amostras. Espera-se que o procedimento de desbaste utilizado produza trincas na superfície das amostras com tamanhos da ordem daqueles calculados pela Equação (1). Assim, a fratura dos vidros de escória é causada pelos defeitos superficiais produzidos na etapa de desbaste das amostras.

O aumento na resistência mecânica com a cristalização do vidro de escória provavelmente só depende da fração cristalizada na amostra (aumento de $\mathrm{K}_{\mathrm{IC}}$ ). Em outras palavras, desde que exista uma alta fração cristalizada no volume do material, a resistência mecânica parece ser independente do tamanho de cristais ou poros, no intervalo de tamanhos estudados. Isso ocorre porque o defeito superficial responsável pela fratura é sempre muito maior que o maior cristal ou poro. $\mathrm{O}$ aumento da resistência mecânica observado nas vitrocerâmicas de escória com alta fração volumétrica cristalizada pode ser causado por um aumento no $\mathrm{K}_{\mathrm{IC}}$, devido à cristalização.

As microestruturas mostradas nas Figuras $6 \mathrm{a}$ e 6b, para os tratamentos em $\mathrm{T}_{\mathrm{n}}=620-625^{\circ} \mathrm{C}$ e $720-725^{\circ} \mathrm{C}$, respectivamente, dão uma idéia do grau de refinamento dos cristais obtidos pelo processo 
vitrocerâmico, que não encontra similares nos processos de fabricação de cerâmicas convencionais. Após polimento, essas amostras apresentam superfície bastante lisa e lustrosa, com brilho equivalente aos encontrados em rochas como o mármore e o granito (após passarem por processos de polimento superficial). Essa propriedade confere ao material aparência bastante atraente para aplicações como revestimentos em construção civil. Exemplos das amostras obtidas nesse trabalho podem ser vistos na Figura 7.

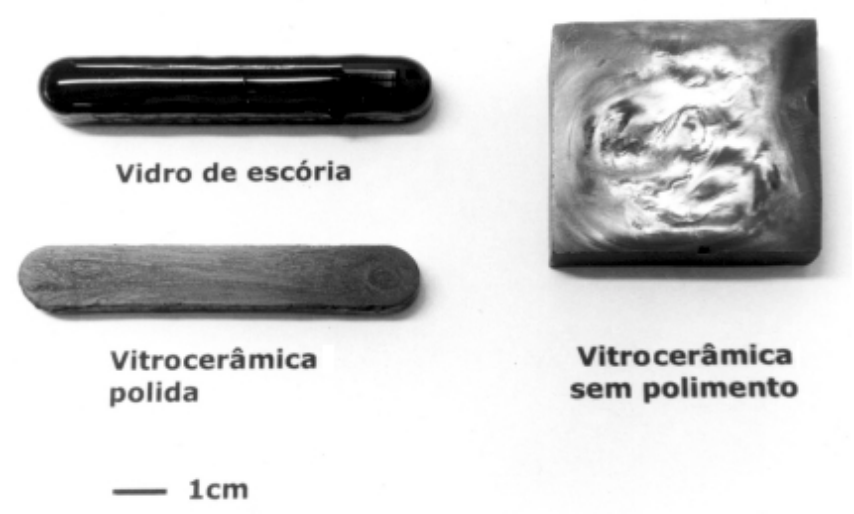

Figura 7. Amostras de vidro e vitrocerâmica, polida e sem polimento, produzidas a partir da escória de aciaria da Usiminas

Em resumo, foi demonstrada a possibilidade de se produzir vidros e vitrocerâmicas a partir de escória de aciaria, com boa resistência mecânica e aspecto visual agradável, que apresentam grande potencial técnico de utilização como revestimentos em construção civil $^{13}$.

\section{CONCLUSÕES}

Os experimentos descritos neste trabalho permitem concluir que é possível obter vidros a partir de escória de aciaria, com o devido ajuste da composição química da mistura através de adições de areia e carbonato de sódio. Com uma mistura contendo $60 \%$ em peso de escória, $35 \%$ areia e $5 \% \mathrm{Na}_{2} \mathrm{O}$ (após fusão a $1350{ }^{\circ} \mathrm{C}$ ), é possível produzir placas de vidros e vitrocerâmicas suficientemente grandes para utilização como revestimento em construção civil. $\mathrm{O}$ vidro obtido a partir dessa mistura apresenta fina cristalização volumétrica. Uma solução sólida próxima à augita ou uma mistura de piroxênios com composições semelhantes à da augita constituem a principal fase cristalina formada. A wollastonita ocorre como segunda fase minoritária. Com um alto grau de cristalização, resultante de tratamentos em temperaturas da ordem de $750{ }^{\circ} \mathrm{C}$, pode-se obter um material com resistência mecânica 50\% maior que a das amostras vítreas. Tratamentos térmicos de nucleação na faixa de 610 a $720{ }^{\circ} \mathrm{C}$ não influenciam a resistência à flexão em 3 pontos. A fratura do material é produzida principalmente por defeitos superficiais muito maiores que o tamanho dos cristais ou poros existentes em sua microestrutura, de modo que variações no tamanho dos mesmos não acarretam mudanças significativas no comportamento mecânico sob flexão do material, na faixa de tamanhos estudada. Com acabamento superficial, a vitrocerâmica de escória de aciaria torna-se lisa e de brilho lustroso e apresenta aspecto visual similar aos obtidos para os mármores e granitos comerciais.

\section{AGRADECIMENTOS}

Os autores agradecem à Usiminas pela infra-estrutura e suporte financeiro, à CAPES pela bolsa de doutorado a E. B. Ferreira e ao CCDM pelas análises de MEV. O suporte financeiro pelo PRONEX também é apreciado.

\section{REFERÊNCIAS}

1. Veasey, T. J.; Miner. Sci. Engng. 1973, 2, 92.

2. Hlavác, J.; The Technology of Glass and Ceramics: An Introduction, Elsevier Scientific Publishing Company: New York, 1983.

3. Fredericci, C.; Zanotto, E. D.; Ziemath, E. C.; J. Non-Crystal. Solids 2000, $273,64$.

4. Kislitsyn, B. F.; Sas, R. I.; Golius, T. E.; Polishchuk, N. A.; Glass Ceram., NY, Consultants Bur. Transl. 1981, 1-2, 13.

5. Rabinovich, E. M. Em Nucleation and Crystallization in Glasses. Advances in Ceramics; Simmons, J. H.; Uhlmann, D. R.; Beall, G. H., eds.; The American Ceramic Society: Columbus, 1982, p. 334.

6. Marotta A.; Buri A.; Branda F.; Saiello S. Em Nucleation and Crystallization in Glasses. Advances in Ceramics; Simmons, J. H.; Uhlmann, D. R.; Beall, G. H., eds.; The American Ceramic Society: Columbus, 1982, p. 146

7. Ray, C. S.; Day, D. E.; J. Am. Ceram. Soc. 1990, 2, 439.

8. Xu, X. J.; Ray, C. S.; Day, D. E.; J. Am. Ceram. Soc. 1991, 5, 909.

9. Weinberg, M. C.; J. Am. Ceram. Soc. 1991, 8, 1905.

10. Kelton, K. F.; J. Am. Ceram. Soc. 1992, 9, 2449.

11. Ray, C. S.; Day, D. E.; J. Am. Ceram. Soc. 1997, 12, 3100.

12. Ferreira, E. B.; Zanotto, E. D.; Scudeller, L. A. M.; Glass Sci. Technol. 2002, 2, 75 .

13. Ferreira, E. B.; Zanotto, E. D.; Fredericci C.; Scudeller, L. A. M.; Br INPI PIO005482, 2000. 